\title{
Determinantes da Sindrome Pré-menstrual: Análise de Aspectos Clínicos e Epidemiológicos
}

Autora: Clarissa Mendes Nogueira

Orientador: Prof. Dr. João Luiz Carvalho Pinto e Silva

Tese de Doutorado apresentada à Faculdade de Ciências Médicas da Universidade Estadual de Campinas - UNICAMP, em 25/10/98.

A sindrome pré-menstrual (SPM) é condição mal definida e mal compreendida, não havendo consenso na maioria dos seus aspectos. Com o objetivo de discutir seus determinantes, realizou-se estudo descritivo de corte transversal, sobre presença e intensidade de sintomas no período pré-menstrual em 254 mulheres de 20 a 44 anos sem condição patológica que pudesse interferir no quadro. Foram identificados quatro grupos: as sem sintomas, que corresponderam a $13,8 \%$; as com forma leve, $22,4 \%$; as com forma moderada, totalizando $20,5 \%$, e as identificadas como forma grave, que foram $43,8 \%$. Utilizando-se análise por regressão logística, odds ratio e testes de confiança constatou-se associação da forma grave com viver com companheiro, ter sido submetida à ligadura tubária ou não trabalhar fora. Quanto a idade, cor, qualidade do relacionamento conjugal, idade à primeira gestação e à menarca, uso de anticoncepcionais hormonais, atividade sexual e suas disfunções, gestações, abortamentos, uso de cafeína, tabagismo, escolaridade e renda, não houve diferenças significativas. A forma grave foi mais prevalente nas mulheres que têm dismenorréia ou ciclo irregular. Os antecedentes de doenças psiquiátricas, hipertensão na gestação, asma, alergias, calculose renal, convulsões e artrite não mostraram diferenças. Entre as pacientes com forma grave o sintoma mais relatado foi irritabilidade $(88 \%)$, seguido por cansaço em $70,9 \%$, depressão e cefaléia $(61,8 \%$ cada um), sendo que $94 \%$ apresentavam mais de um sintoma, com $76,4 \%$ associando sintomas físicos e psíquicos. Poucas procuraram tratamento sendo que, segundo as que o fizeram, os profissionais não acharam que estavam diante de um problema a ser tratado. Concluiuse que a SPM afetou quase a totalidade dessas mulheres, metade delas intensamente, com sintomas múltiplos, geralmente por poucos dias, sendo associada tanto a condições quanto psicossociais.

Palavras-chave: Tensão pré-menstrual. Laqueadura tubárea. Dismenorréia. Ciclo menstrual.

\section{Frequêencia de Neoplasias Intra-epiteliais Cervicais em Mulheres Portadoras do Virus da Imunodeficiência Humana}

Autor: Antonio Pedro F. Auge

Orientador: Prof. Dr. Sebastião Piato

Tese de Mestrado. Curso de Pós-Graduação em Medicina. Área de Concentração em Tocoginecologia. Departamento de Obstetrícia e Ginecologia da Santa Casa de São Paulo. Apresentada em 18/12/97.

Introdução: as evidências de que estados de imunodepressão são responsáveis por aumento do risco para câncer do colo uterino motivaram a realização de vários estudos; a finalidade dos mesmos tem sido verificar a freqüência de neoplasias intra-epiteliais cervicais (NIC) em mulheres soropositivas para HIV. Tais estudos demonstraram aumento do risco para essas lesões do colo uterino em soropositivas, particularmente em mulheres com baixos valores de CD4+. Em nosso meio, não encontramos estudos epidemiológicos completos sobre o tema.

Proposição. Avaliação da freqüência de neoplasias intraepiteliais cervicais em mulheres portadoras do vírus da imunodeficiência humana.

Material e Método: nosso material de estudo foi constituído por 99 pacientes soropositivas para HIV e 104 soronegativas. O diagnóstico de infecção pelo vírus HIV foi feito através de dois testes ELISA, complementados por teste Western blot. Todas as pacientes do grupo de estudo e do grupo controle foram submetidas a citologia oncológica do colo uterino e colposcopia. As pacientes que apresentaram lesões suspeitas à colposcopia foram submetidas a biopsia. Quando o exame histopatológico revelou presença de NIC I, nenhum outro procedimento foi realizado. Nos casos de NIC II ou NIC III, realizou-se conização. Os dados deste estudo foram processados em EPI-INFO v6.01. Para avaliação da significância dos resultados, utilizamos teste qui-quadrado.

Resultados: no grupo de estudo foram diagnosticados 15 casos de neoplasias intra-epiteliais cervicais $(15,2 \%)$, sendo dez NIC I, uma NIC II e quatro NIC III. No grupo controle encontramos quatro neoplasias intraepiteliais cervicais $(3,8 \%)$, sendo uma NIC I e três NIC III. O teste estatístico qui-quadrado indicou que a diferença encontrada entre os dois grupos possui significância.

Palavras-chave: AIDS. HIV. Neoplasia intraepitelial cervical. 